\title{
Air Monitoring and Assessment of Occupational Exposure to Peracetic Acid in a Hospital Environment
}

\author{
Marco PACENTI ${ }^{1 *}$, Stefano DUGHERI ${ }^{1}$, Pierpaolo BOCCALON ${ }^{1}$, \\ Giulio ARCANGELI' ${ }^{1}$, Piero DOLARA ${ }^{2}$ and Vincenzo CUPELLI' \\ ${ }^{1}$ Occupational Health Division, Department of Public Health, University of Florence, Largo Palagi 1, Florence \\ 5013, Italy \\ ${ }^{2}$ Department of Pharmacology, University of Florence, Viale Pieraccini 6, Florence 50139, Italy
}

Received November 19, 2008 and accepted September 8, 2009

\begin{abstract}
A new automated method based upon solid phase micro-extraction (SPME)/fast gas chromatography-mass spectrometry (GC-MS) was developed for the quantitative determination of airborne peracetic acid (PAA). The method is suitable for the quick assessment of brief acute exposure as well as for long-term environmental monitoring of PAA and can assist in improving safety and environmental quality in workplaces where disinfectants are used. During a monitoring campaign in the Regional Hospital of Florence, Italy, the 8-h average air concentration of PAA was $1 / 10$ of the threshold limit value of time weighted average in $87 \%$ of the clinical units tested. However, the application of the new SPME method showed that short-term exposure to PAA could be relatively elevated in some hospital units with poor ventilation, allowing prompt intervention in order to reduce worker exposure to this potentially toxic compound.
\end{abstract}

Key words: Peracetic acid, Hospital environment, Solid phase microextraction, Occupational exposure, Risk assessment

Peracetic acid (PAA, CAS Number 79-21-0) was introduced as an antibacterial agent in 1955. It has a broad spectrum of activity, including bacteria, spores, molds, yeasts, algae and viruses ${ }^{1,2)}$. PAA, a possibly safe oxidizing agent, is being increasingly used recently, especially as a high-level disinfectant in hospital settings. However, if used at high concentration, it may cause skin and mucosal irritation and its vapors are extremely irritating to eyes, nose and throat ${ }^{3}$.

There are a few methods to detect PAA in the gas phase described in the literature, such as photometry ${ }^{4,5)}$, spectroscopy $\left.^{6}\right)$ or gas-7) $^{7}$ and liquid-chromatography ${ }^{8-10)}$ with and without derivatization. But all these methods are not sufficiently sensitive and furthermore require handling of many chemicals, complicated cleaning and extraction procedures, and the use of cumbersome equipment which may interfere with job performance.

*To whom correspondence should be addressed.

E-mail: marco.pacenti@unifi.it
Solid phase micro-extraction (SPME), a solvent-free technique, incorporates sampling, isolation and enrichment into one step. It has been proposed since 1998 as a passive device ${ }^{11,12)}$ for field and personal sampling, both as "rapid-SPME" with completely exposed fibers for short-term sampling and for determination of "timeweighted average (TWA)-SPME". In the latter case the fiber is retracted inside the needle up to $0.1-3.5 \mathrm{~cm}$.

Acceptable limits for PAA have been suggested by the Institut National de Recherche et Sècuritè (INRS) and by the Subcommittee on Consequence Assessment and Protective Actions (SCAPA). INRS ${ }^{13)}$ proposed a Threshold Limit Value (TLV) as TWA for PAA of $0.62 \mathrm{mg} / \mathrm{m}^{3}(0.2 \mathrm{ppm})$ and a TLV as Short Time Exposure Limit (STEL) of $1.56 \mathrm{mg} / \mathrm{m}^{3}$. The PAA Acute Exposure Guidelines Level values ${ }^{14}$ (AEGL 1, AEGL 2 and AEGL 3) are $0.52,1.6$ and $60 \mathrm{mg} / \mathrm{m}^{3}$ for $10 \mathrm{~min}$ of exposure.

Since PAA may have severe acute health effects at high concentrations, it seemed important to us to have a method sensitive to quick elevations of PAA in the air 
during handling and disinfecting procedures. For this reason, we developed a new, rapid, economical and automated analytical SPME fast gas chromatography-mass spectrometry (GC-MS) method for the fast quantitative determination of airborne PAA. Here we will describe the method as well as the results of a campaign of environmental monitoring in a hospital setting in Florence, Italy.

A survey carried out in the Regional Hospital of Florence, Italy, showed that Oxyster Plus Long Life PAA (Farmec, Verona, Italy), formed from hydrogen peroxide and $\mathrm{N}$-acetylcaprolactam, was used in fifteen clinical units with a total per-month consumption of 8031 . To prepare the $0.2 \%$ PAA solution, a generator with peroxidic groups was used to obtain the nucleophilic attachment to the carbonyl bond of the $\mathrm{N}$-acetyl in the activator.

To determine airborne PAA exposure in 15 nurses in 15 different clinical units we used the SPME technique, with a $100 \mu \mathrm{m}$ Fast Fit Assemblies (FFA)-SPME polydimethylsiloxane (PDMS) fiber (Supelco, Sigma-Aldrich, Milan, Italy). The fiber was doped for $10 \mathrm{~s}$ in the headspace of a PTFE-capped $4 \mathrm{ml}$ amber vial containing $5 \mu \mathrm{l}$ of methyl-p-tolyl-sulfide (MTS). From the reaction between PAA and MTS, methyl-p-tolyl sulfoxide (MTSO) was obtained. Sampling was performed both by "rapid-SPME" and by "TWA-SPME" (in this case the fiber was retracted in the needle to a distance of $Z=0.3 \mathrm{~cm}$ ) exposing the fiber in the air for $15 \mathrm{~s}$ and $8 \mathrm{~h}$, respectively, under non-equilibrium conditions. After sampling, PAA was analyzed with fast GC/MS with a Shimadzu GC 2010 (Shimadzu Italia, Milan, Italy), using an SLB5-MS column by Supelco $(5 \mathrm{~m} \times 0.10 \mathrm{~mm} \times 0.4 \mu \mathrm{m}$ film thickness). The ionization was performed with a QP 2010 series MS detector operating in the electron impact (EI) mode. MS analysis was operated by the new fast automated scan/selective ion monitoring (SIM) technique (FASST) acquisition mode with scan range of $\mathrm{m} / \mathrm{z}$ 40-200; for MTSO determination, the mass number of the target ion was $m / z=138$ and the confirming ion was $\mathrm{m} / \mathrm{z}=154$. Oven settings were $60^{\circ} \mathrm{C}$ held for $0.30 \mathrm{~min}$, with a ramp of $150^{\circ} \mathrm{C} / \mathrm{min}$ up to $100^{\circ} \mathrm{C}$ and $50^{\circ} \mathrm{C} / \mathrm{min}$ up to $250^{\circ} \mathrm{C}$. Inlet pressure and column flow were 348.8 $\mathrm{KPa}$ and $1.21 \mathrm{ml} / \mathrm{min}$, respectively. The injector $\left(280^{\circ} \mathrm{C}\right)$ was set in split mode 10:1. Full automation of the procedure was achieved using a Gerstel MPS2 autosampler equipped with Multi Fiber Exchange (SRA Instruments, Milan, Italy). To calibrate the fiber, PAA vapor was generated in a dynamic system by a syringe-pump Harvard Plus 11 (Harvard Apparatus, Holliston, United States), equipped with a $1 \mathrm{ml}$ gas-tight syringe set to $2 \mu \mathrm{l} / \mathrm{min}$. The PAA solution was set at $7.8 \mu \mathrm{g} / \mu \mathrm{l}$.

The PAA air concentration $\left(\mathrm{C}_{\mathrm{PAA}}\right.$ air $)$ was calculated according to the following formula:

$$
\mathrm{C}_{\mathrm{PAA} \text { air }}=\mathrm{C}_{\text {Sol }} \mathrm{F}_{\text {syringe }} / \mathrm{F}_{\text {air }}
$$

where, $\mathrm{C}_{\mathrm{PAA}}$ air is the concentration of analyte in air $(\mu \mathrm{g} / \mathrm{l}), \mathrm{C}_{\mathrm{Sol}}$ is the concentration of the solution $(\mu \mathrm{g} / \mu \mathrm{l})$, $\mathrm{F}_{\text {syringe }}$ is the syringe-pump flow $(\mu \mathrm{l} / \mathrm{min})$, and $\mathrm{F}_{\text {air }}$ is the air flow (1/min).

The experimental sampling rates (SR) of the "rapidSPME" and "TWA-SPME" system were obtained using the equation:

$$
\mathrm{SR}=\text { uptake } / \mathrm{C}_{\mathrm{PAA}} \text { air }
$$

The uptake is the slope of the line obtained by correlating the mass of PAA adsorbed on the fiber with the sampling time at calibrated air concentrations $\left(\mathrm{C}_{\mathrm{PAA} \text { air }}\right)$. The theoretical SR of the SPME passive sampling system with "TWA-SPME" was expressed as:

$$
\text { Theoretical SR }=\left(D_{g} \times A\right) / Z
$$

where $\mathrm{Z}=$ distance between the needle opening and the fiber upper surface, $A=$ surface of the needle opening $\left(0.00086 \mathrm{~cm}^{2}\right)$, and $\mathrm{D}_{\mathrm{g}}=$ analyte diffusion coefficient in the air (for PAA $0.149 \mathrm{~cm}^{2} / \mathrm{s}$ by Fuller-Schettler-Giddings equation).

Table 1 describes the principal characteristics of the fifteen clinical units (dimension, type of sterilization, ventilation and aspiration systems, volumes of PAA solution used during filling operations). In two units (ns 9 and 14) lavaendoscopes (model Autoscope 2, Labcaire System Ltd, Clevedon, United Kingdom) were present, equipped with an apparatus made of an activated carbon filter for trapping disinfectant fumes. Most units had no artificial ventilation except units ns 2, 3, 4 and 5, where a mechanical ventilation system of turbulent flow type was installed and set at 15 changes $/ \mathrm{h}$. This system distributed the external air evenly in the room, achieving uniform air quality, temperature and air velocity. In unit n 10 an aspirating hood was installed (model G17S, PCI Medical Inc, Deep River, United States) with a face velocity of $13.7 \mathrm{~m} / \mathrm{min}$. In most units the operations were manual and cleaning devices were basins or tubes. Personnel used long-sleeved waterproof gowns, nitrile gloves, goggles and disposable charcoal-impregnated face masks.

The evaluation of airborne PAA exposure was made by means of personal sampling in the breathing zone of the workers and included the following settings (Table 1): (1) background exposure to airborne PAA in the room independently of specific manipulations; (2) disposal of the exhausted solution ("emptying"); (3) filling of basins, lavaendoscopes and tubes with activated solution ("filling"); (4) persistence of pollution in the room while the operator is busy tidying the work space ("decay"); (5) immersion of devices in the activated solution of PAA ("routine activity"). 


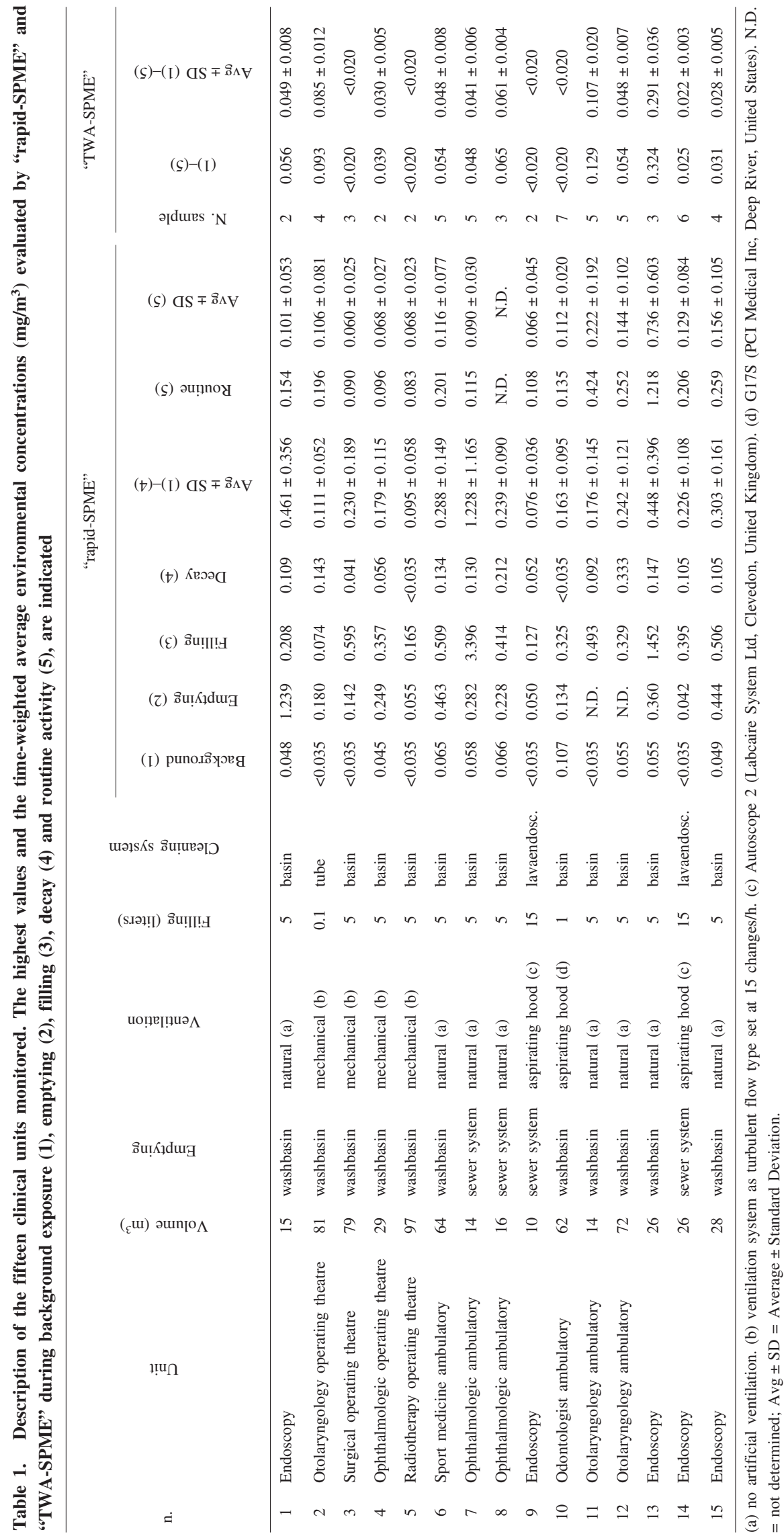




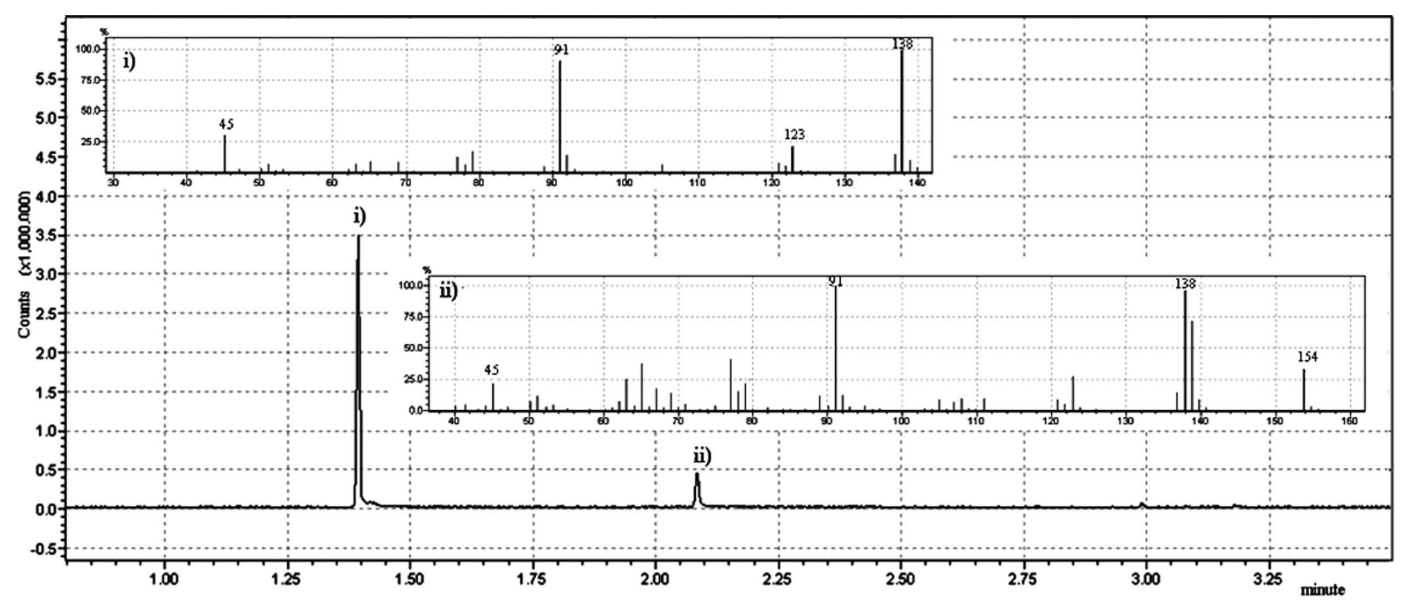

Fig. 1. Fast GC-MS chromatogram and EI mass spectrum of the i) MTS, ii) MTSO.

Short-term 10-min exposure was monitored using forty SPME fibers, each for $15 \mathrm{~s}$ in sequence for "rapid SPME" sampling. A multi-data logger model BABUC/A (LSI, Milan, Italy) was employed to measure microclimatic parameters during air sampling (temperature, relative humidity and air velocities).

The main goal of the work was to determine the "instantaneous" environmental concentrations of PAA using the "rapid-SPME" method and to compare the results with the long-term sampling by "TWA-SPME". An additional goal was the minimization of GC analysis time using a narrow bore capillary column (Fig. 1). The limits of quantification (LOQ) in the SIM mode for "rapid-SPME" and "TWA-SPME" were 0.035 (for $15 \mathrm{~s}$ sampling) and $0.020 \mathrm{mg} / \mathrm{m}^{3}$ (for $8 \mathrm{~h}$ sampling) and were evaluated with a signal-to-noise ratio $>5$ and a peak area in the linear range of the calibration curve. The method for "TWA-SPME" sampling $(\mathrm{Z}=0.3 \mathrm{~cm})$ had $8 \%$ relative standard deviation (RSD, $\mathrm{n}=5$ ) at low $\mathrm{C}_{\mathrm{PAA}}$ air $\left(0.070 \mathrm{mg} / \mathrm{m}^{3}\right)$ and $9 \%$ RSD $(\mathrm{n}=5)$ at high $\mathrm{C}_{\mathrm{PAA}}$ air $\left(3.0 \mathrm{mg} / \mathrm{m}^{3}\right)$, while "rapid-SPME" sampling had $11 \%$ RSD $\left(0.040 \mathrm{mg} / \mathrm{m}^{3}\right)$ and $10 \% \operatorname{RSD}\left(1.2 \mathrm{mg} / \mathrm{m}^{3}\right)$. Figure $2 \mathrm{a}, \mathrm{b}$ shows plots of the amount of absorbed PAA as a function of exposure time for both sampling methods to determine SR. The slope of the curve represents the uptake of PAA on SPME fibers as indicated in equation 2. As to "TWA-SPME" with $\mathrm{Z}=0.3 \mathrm{~cm}$, the experimental average SR value was $0.0235 \mathrm{ml} / \mathrm{min}$ (Fig. 2b), in good agreement with theoretical SR value $(0.0256 \mathrm{ml} / \mathrm{min})$ calculated by equation 3. The experimental average SR value for "rapid-SPME" was equal to $7.7884 \mathrm{ml} / \mathrm{min}$ (Fig. 2a). The cross reactivity to hydrogen peroxide was negligible in the concentration ranges of PAA. No significant change in mass adsorbed was observed after storage $\left(-20^{\circ} \mathrm{C}\right)$ for one week. The robustness of the fiber allowed more than 150 analyses for each fiber. The a

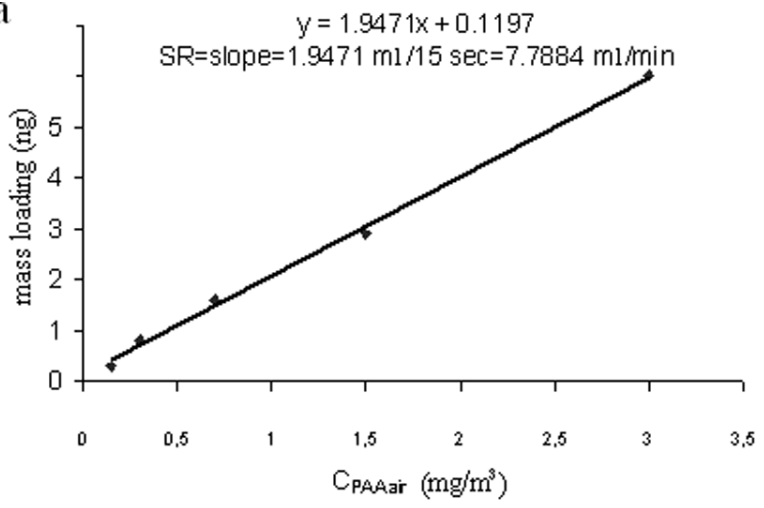

b

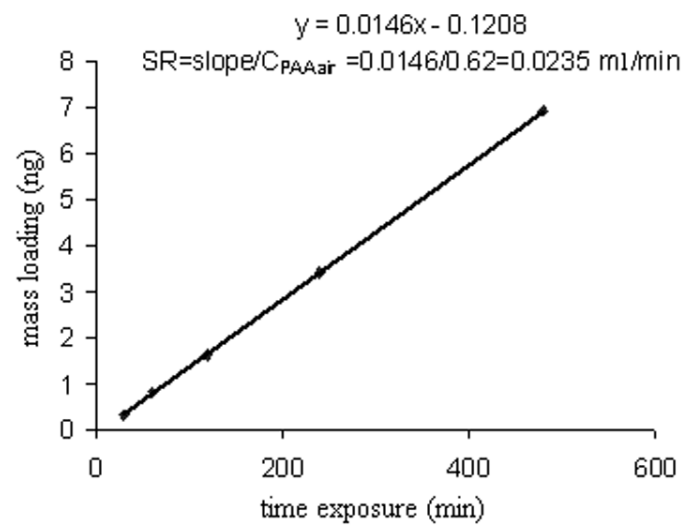

Fig. 2. a, Weight of PAA (ng) formed at $15 \mathrm{~s}$ exposure time as a function of various $C_{\text {PAA air }}\left(\mathrm{mg} / \mathrm{m}^{3}\right)$ by "rapid-SPME". b, Uptake rate (ng/s) for PAA by "TWA-SPME" with $Z=0.3 \mathrm{~cm}$ $\left(C_{\text {PAA air }}=0.62 \mathrm{mg} / \mathrm{m}^{3}\right)$.

ranges in microclimatic parameters registered in the fifteen units during the PAA environmental monitoring were: air temperature $\left(19.1-23.7^{\circ} \mathrm{C}\right)$, relative humidity (45.4-77.9\%), air speed $(0.4-1.5 \mathrm{~cm} / \mathrm{s})$.

With rapid SPME we measured the average environ- 
mental concentrations (10 min) of PAA during step 1-4, which include all the phases of the handling of the solution. Among the fifteen units monitored, this average was higher than AEGL 1 only in unit $\mathrm{n} .7\left(1.228 \pm 1.165 \mathrm{mg} / \mathrm{m}^{3}\right)$. In unit $\mathrm{n} .13$ we observed the highest average values $\left(0.736 \pm 0.603 \mathrm{mg} / \mathrm{m}^{3}\right)$ for setting 5 (defined as "routine" in Table 1). The highest instantaneous concentration levels (range $0.414-3.396 \mathrm{mg} / \mathrm{m}^{3}$ ) were noticed when the filling (setting 3) was made in devices with a large evaporating surface (average diameter of the basins, $42 \mathrm{~cm}$ ), in rooms without localized aspiration (units n. 6, 7, 8, 11, 13, 15 ) and in setting 2 ("emptying"), range $0.360-1.239 \mathrm{mg} / \mathrm{m}^{3}$ (units $\mathrm{n} .1,6,13,15)$. In the endoscopic wards using lavaendoscopes (units n. 9, 14), the exhausted solution was discharged in closed circuits. The units using natural ventilation (n. 1, 6, 7, 8, 11, 12, 13, 15) showed a higher average level of PAA $\left(0.423 \mathrm{mg} / \mathrm{m}^{3}\right)$ than those (n. 2 , $3,4,5,9,10,14)$ with assisted ventilation $\left(0.154 \mathrm{mg} / \mathrm{m}^{3}\right)$ for short-term exposure $(10 \mathrm{~min})$. For long-term sampling by "TWA-SPME", the average concentration of PAA was 1/10 lower than TLV-TWA except in units n. 2, 11 and 13.

These data are the first in the literature reporting a method for high-throughput automated analysis of airborne PAA using an MFX/SPME fast GC-MS robotic system. The high sensitivity of the method evaluates PAA concentrations with extremely short sampling periods, producing instantaneous values of PAA levels. In addition SPME reduces analytical costs, is easily applicable and uses no solvents, therefore having no environmental impact.

Evaluation of PAA exposure levels is essential to efficiently organize prevention of risks from using this potentially toxic chemical. We were able to identify high exposure steps during the handling of PAA in our hospital with this new method, which then prompted the adoption of approaches to minimize exposure such as staff training, mechanical ventilation and the use of lavaendoscopes equipped with a specific aspiration system.

\section{Acknowledgements}

The authors gratefully acknowledge Dr. Elena Franchi, Alice Bonacchi for technical assistance and Mary C. Forrest for linguistic revision of the manuscript.

\section{References}

1) Alasri A, Valverde M, Roques C, Michel G, Cabassud C, Aptel P (1993) Sporocidal properties of peracetic acid and hydrogen peroxide, alone and in combination, in comparison with chlorine and formaldehyde for ultra- filtration membrane disinfection. Can J Microbiol 39, 52-60.

2) Samrakandi MM, Roques C, Michel G (1994) Activité sporocide de l'hypochlorite de sodium et de l'acide peracétique seuls ou associés sur spores libres, fixées ou en biofilm (Sporocidic activity of sodium hypochlorite and peracetic acid alone or combined against free or fixed spores or on biofilm). Pathol Biol (Paris) 42, 432-7 (in French).

3) Health and Safe Executive. SIM 07/2003/14 Endoscope Disinfection - Alternatives to Glutaraldehyde. http://www. hse.gov.uk/aboutus/meetings/iacs/acts/watch/watch64.htm. Accessed November 18, 2008.

4) Pinkernell U, Lüke HJ, Karst U (1997) Selective photometric determination of peroxycarboxylic acids in the presence of hydrogen peroxide. Analyst 122, 567-71.

5) Effkemann S, Brødsgaard S, Mortensen P, Linde SA, Karst U (2000) Spectrophotometric and direct-reading methods for the analysis of gas phase peroxyacetic acid. Fresenius J Anal Chem 366, 361-4.

6) Higashi N, Yokota H, Hiraki S, Ozaki Y (2005) Direct determination of peracetic acid, hydrogen peroxide, and acetic acid in disinfectant solutions by far-ultraviolet absorption spectroscopy. Anal Chem 77, 2272-7.

7) Di Furia F, Prato M, Scorrano G, Stivanello M (1988) Gas-liquid chromatographic method for the determination of peracids in the presence of a large excess of hydrogen peroxide. Part 2. Determination in alkaline solutions. Analyst 113, 793-5.

8) Hecht G, Héry M, Hubert G, Subra I (2004) Simultaneous sampling of peroxyacetic acid and hydrogen peroxide in workplace atmospheres. Ann Occup Hyg 48, 715-21.

9) Henneken H, Assink L, de Wit J, Vogel M, Karst U (2006) Passive sampling of airborne peroxyacetic acid. Anal Chem 78, 6547-55.

10) Pinkernell U, Effkemann S, Karst U (1997) Simultaneous HPLC determination of peroxyacetic acid and hydrogen peroxide. Anal Chem 69, 3623-7.

11) Martos PA, Pawliszyn J (1999) Time-weighted average sampling with solid-phase microextraction device: implications for enhanced personal exposure monitoring to airborne pollutants. Anal Chem 71, 1513-20.

12) Pieraccini G, Bartolucci G, Pacenti M, Dugheri S, Boccalon P, Focardi L (2002) Gas chromatographic determination of glutaraldehyde in the workplace atmosphere after derivatization with O-(2,3,4,5,6-pentafluorobenzyl)hydroxylamine on a solid-phase microextraction fibre. J Chromatogr A 955, 117-24.

13) Gagnaire F, Marignac B, Hecht G, Héry M (2002) Sensory irritation of acetic acid, hydrogen peroxide, peroxyacetic acid and their mixture in mice. Ann Occup Hyg 46, 97-102.

14) United States Environmental Protection Agency. Acute Exposure Guideline Levels. http://www.epa.gov/oppt/ aegl/pubs/chemlist.htm. Accessed November 18, 2008. 